\title{
Surgical Management of Gynecomastia-a 10-year Analysis
}

\author{
A. E. Handschin $\cdot$ D. Bietry $\cdot$ R. Hüsler · \\ A. Banic $\cdot$ M. Constantinescu
}

Published online: 17 November 2007

(C) Société Internationale de Chirurgie 2007

\begin{abstract}
Background Gynecomastia is defined as the benign enlargement of the male breast. Most studies on surgical treatment of gynecomastia show only small series and lack histopathology results. The aim of this study was to analyze the surgical approach in the treatment of gynecomastia and the related outcome over a 10 -year period.

Patients and methods All patients undergoing surgical gynecomastia corrections in our department between 1996 and 2006 were included for retrospective evaluation. The data were analyzed for etiology, stage of gynecomastia, surgical technique, complications, risk factors, and histological results.

Results A total of 100 patients with 160 operations were included. Techniques included subcutaneous mastectomy alone or with additional hand-assisted liposuction, isolated liposuction, and formal breast reduction. Atypical histological findings were found in $3 \%$ of the patients (spindlecell hemangioendothelioma, papilloma). The surgical revision rate among all patients was $7 \%$. Body mass index and a weight of the resected specimen higher than $40 \mathrm{~g}$ were identified as significant risk factors for complications $(p<0.05)$.

Conclusions The treatment of gynecomastia requires an individualized approach. Caution must be taken in performing large resections, which are associated with increased complication rates. Histological tissue analysis should be routinely performed in all true gynecomastia
\end{abstract}

A. E. Handschin $(\bowtie) \cdot$ D. Bietry $\cdot$ R. Hüsler · A. Banic ·

M. Constantinescu

Department of Plastic and Reconstructive Surgery, University

Hospital of Bern, CH-3010 Berne, Switzerland

e-mail: handschin73@hotmail.com corrections, because histological results may reveal atypical cellular pathology.

Gynecomastia is defined as the benign glandular proliferation of the male breast causing enlargement and thus a feminine appearance [1]. In some patients, especially in the adolescent, gynecomastia may regress spontaneously [2]. In persistent cases, pain, galactorrhea, or cancer phobia and other psychological effects, including embarrassment, may lead to the necessity of treatment. Medical treatment may be effective at an early stage in which glandular tissue still proliferates [1]. However, with time, the tissue will become increasingly fibrotic and thus fail to respond to medical therapy [1]. In such cases the surgical therapy of gynecomastia is commonly accepted as the standard treatment.

Surgical approaches are numerous and include the removal of the excessive glandular tissue and skin by subcutaneous mastectomy, breast reduction, liposuction, or a combination of these techniques [3-9].

To date, male breast diseases, including gynecomastia, are not treated by one speciality of surgeons alone, but by general, visceral, thoracic, and plastic surgeons. The present literature on gynecomastia reflects a variety of approaches and describes multiple individual techniques. Unfortunately, most studies have small patient numbers and lack a standardized classification, etiology, andespecially-histopathological findings. However, all these aspects are necessary to improve accuracy in the appropriate choice of the surgical approach and to allow comparison with results from other studies. The present study was designed to provide systematic evaluation of the results of a 10-year period in surgical treatment of gynecomastia with special focus on techniques, complications, and outcome. 


\section{Patients and methods}

A retrospective analysis of all patients undergoing surgery for gynecomastia between November 1996 and March 2006 was conducted at the Department of Plastic Surgery at the University Hospital of Berne. The preoperative grading was performed using the Simon classification for gynecomastia [10]: grade I, minor breast enlargement without skin redundancy; grade IIa, moderate breast enlargement without skin redundancy, grade IIb, moderate breast enlargement with minor skin redundancy; grade III, severe breast enlargement with skin redundancy simulating a female breast.

The clinical evaluation included the etiology and categorization of true gynecomastia (hypertrophy of stroma and glandular cells) into five groups: (1) idiopathic (including adolescence/pubertal type), (2) endocrine type, (3) tumor-related type, (4) metabolic type (e.g., cirrhosis, diabetes, starvation), and (5) druginduced type. Patients treated for pseudogynecomastia, a condition in which male breast enlargement is caused by adipose hypertrophy and obesity, were also included in the study. Patients underwent ultrasound imaging of enlarged breasts prior to surgery in all cases of unilateral gynecomastia, in the presence of mastodynia, and in cases where enlargement of the male breast had occurred within a short period of time (less than 6 months). If an endocrine etiology was suspected, the patient underwent an endocrinological evaluation first, including measurement of hormone serum levels. In these cases, surgery was performed only after completion of the appropriate medical therapy.

The operations performed included subcutaneous mastectomy, subcutaneous mastectomy with additional liposuction, breast reduction, and isolated liposuction. The operation was performed with either local or general anesthesia. Single shot antibiotic prophylaxis was administered routinely (Cefuroxine $1.5 \mathrm{~g}$ i.v.). The subcutaneous mastectomy was performed using a semicircular-periareolar inferior incision as described by Webster [11]. In the presence of excessive skin, periareolar skin reduction was performed with the Benelli pursestring technique [12], which was performed in both grades IIb and III gynecomastia. In those cases of grade III gynecomastia where a pursestring did not reduce enough of the excessive skin, a formal breast reduction with a circumareolar and vertical incision including skin resection was performed. Medialization of the nipple-areolar complex was performed if necessary; a semicircular skin excision with de-epithelialization was combined with mastopexia in cases of severe ptosis. Additional liposuction was performed in patients in whom excessive fat tissue would compromise the esthetic results following open resection of the hypertrophic gland.
The exclusive use of liposuction was reserved for cases with pseudogynecomastia in the absence of a palpable hypertrophic gland. The resected specimens underwent histological analysis. A drain was routinely placed in the resulting epipectoral cavity and remained for $1-3$ days until the drainage volume decreased under $20 \mathrm{ml} / 24 \mathrm{~h}$. All patients received a compression dressing for 1-2 weeks following the operation. The patients were seen in an early (first 2 postoperative weeks) and a late follow-up visit. The following data were analyzed: age, weight, height, medical history, operating time, weight of resected specimens, histological findings, complications, and recurrence.

All results are given as percentage of the patients, except for analysis of the surgical procedures, which are expressed as percentage of the total procedures. Statistical analysis of the data was performed using a post-hoc $t$-test, Fisher's exact test, and $\chi^{2}$ test using the G-Power $\AA$ version 2.1.2 software.

\section{Results}

\section{Patient data}

Between 1996 and 2006, a total of 160 operations were performed in 100 patients. (unilateral, $n=40$; bilateral, $n=60$ ). The mean patient age was $28.9 \pm 14$ years (range: 13.2-75 years). The mean body mass index (BMI) was $24.98 \pm 14 \mathrm{~kg} / \mathrm{m}^{2}$ (range: $17.6-39.1 \mathrm{~kg} / \mathrm{m}^{2}$ ). Also of note, $38 \%$ of the patients were active smokers ( $>10$ cigarettes/ day).

Preoperative grading according to the Simon classification included patients with stage I $(n=3)$, stage IIa $(n=42)$, stage IIb $(n=31)$, and stage III $(n=24)$ gynecomastia (Fig. 1). The underlying cause included the following types: idiopathic/adolescence (55\%), pseudogynecomastia (16\%), endocrine (10\%), drug-induced (8\%), metabolic (6\%), and tumor-related (5\%).

Mastodynia was present in $46 \%$ of the patients preoperatively. Twenty-six percent of patients received preoperative medical therapy (systemic antiestrogen, tamoxifen therapy). The operation was carried out under general anesthesia (80\%, stages I-III) or with local anesthesia (20\%, stages I-IIa).

\section{Surgical procedures}

The operative techniques (Table 1) included subcutaneous mastectomy alone ( $n=90$ operations (56\%), stages I-IIb), subcutaneous mastectomy with additional liposuction ( $n=44$ operations $(28 \%)$, stages IIa-III), subcutaneous mastectomy with mastopexy and medialization of nipple- 


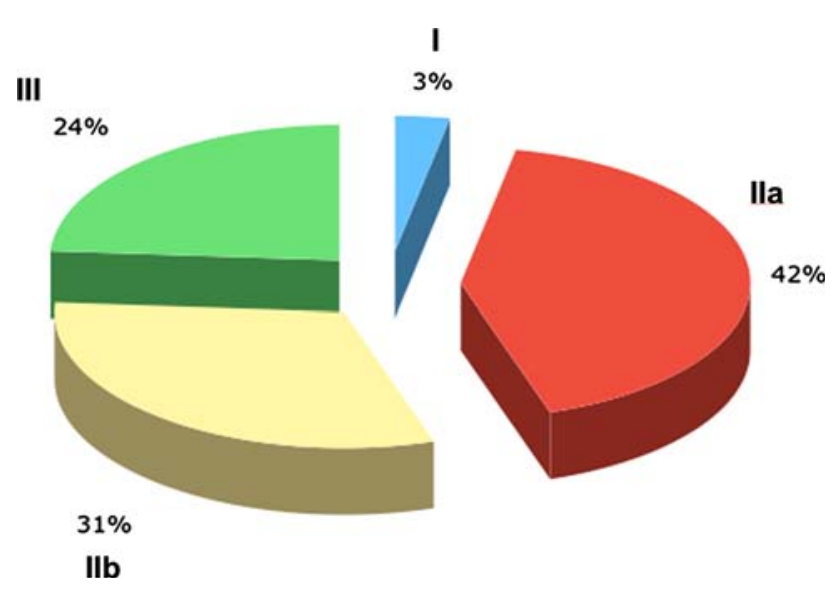

Fig. 1 Preoperative staging (Simon classification) in 100 patients

areolar complex ( $n=11$ operations $(7 \%)$, stage III), isolated liposuction ( $n=11$ operations (7\%), stage IIa-III), and breast reduction ( $n=4$ operations ( $2 \%)$, stage IIb-III). The mean operating time for subcutaneous mastectomy with or without liposuction was $57.7 \pm 21 \mathrm{~min}$ (range: 20-110 $\mathrm{min}$ ), and mean operating time for isolated liposuction was $48 \pm 5 \mathrm{~min}$ (range: $45-75 \mathrm{~min}$ ) ( $t$-test, n.s., $p>0.05$ ). The mean weight of the resected specimen was $92 \pm 44 \mathrm{~g}$ (range: 9-480 g). The histological examination showed true, fibrotic gynecomastia in $78 \%$ of the patients, with ductal hyperplasia present in $36 \%$ of the patients. In two patients, ductal hyperplasia was combined with mild metaplasia and apocrine secretion. Pseudogynecomastia with exclusive fat tissue hypertrophy was described in $17 \%$ of the patients. In three patients (3\%) histological analysis revealed further pathology including hemangioma $(n=1)$, breast papilloma $(n=1)$, and spindle cell hemangioendothelioma $(n=1)$ (Fig. 2). The resection margins of the hemangioendothelioma and papilloma specimen were tumor-free, and no further intervention was necessary.

\section{Complications}

Complications requiring further conservative or operative treatment occurred in a total of $31 \%$ of all patients treated. The complications involved postoperative bleeding and

Table 1 Surgical techniques for the treatment of gynecomastia

Technique ( $n=160$ procedures)

Subcutaneous mastectomy alone

Subcutaneous mastectomy with hand-assisted liposuction

Subcutaneous mastectomy with medialization/mastopexy

Liposuction alone

Breast reduction/skin excision hematoma $(n=9)$, and seroma formation $(n=8)$ (Table 2). Surgical revision became necessary in $7 \%$ of the patients, and the others were successfully treated conservatively. Complications were exclusively observed in preoperative stages IIa-III but did not differ statistically within these three Simon stages.

The weight of the resected specimen correlated significantly with major complication rates $(<40 \mathrm{~g}: 1 \%$ versus $>40$ $\mathrm{g}: 51 \% ; p=0.0158)$. Overweight patients with a BMI greater than $25 \mathrm{~kg} / \mathrm{m}^{2}$ had a significantly higher complication rate (36\% versus $14 \% ; p=0.0373$ ) (Table 3 ). Complication rates were not different in patients treated with subcutaneous mastectomy alone or with additional liposuction (13.9\% versus $15 \%$, Fisher's exact test; $p=0.69$ ). Complications in patients who were active smokers did not differ significantly from those in nonsmokers ( $21 \%$ versus $18 \% ; p=0.125$ ).

Minor complications were observed in $14 \%$ of all patients and included areolar epidermolysis ( $n=7$ patients), prolonged hypesthesia of the nipple-areolar complex $(n=6$ patients), and wound dehiscence/necrosis ( $n=1$ patient). All these were treated conservatively. The majority of the patients $(70 \%)$ experienced reversible hypesthesia of the nipples at the early postoperative control.

The mean follow up was $8.8 \pm 4.5$ months (range: $27-$ 725 days). Figures 3, 4, 5 and 6 illustrate postoperative results. No patients suffered from persisting mastodynia.

There was one recurrence of gynecomastia following isolated subcutaneous mastectomy in a grade IIb gynecomastia (adolescent type, normal endocrine status). The residual breast tissue, which had regrown, was re-excised. An objective analysis of the late complications revealed minimal persistence of excessive soft tissue (dog ear deformity) ( $n=6$ patients), hypertrophic scarring ( $n=3$ patients), and persisting nipple hypesthesia ( $n=2$ patients). None of the late complications required corrective operative treatment.

\section{Discussion}

The surgical approach to the treatment of gynecomastia shows a wide variation in the literature, reflecting the lack of clear guidelines. Early publications focused on surgical excision of the glandular tissue, whereas more recent studies advocate the unique use of liposuction, emphasizing superior esthetic results and decreased complication rates $[6,7,13,14]$. This, however, bears the potential for overlooking atypical pathological findings in the male breast tissue. In view of the above incertitude, it appeared necessary to evaluate the results of a large series in a 10-year experience at one center in which open surgical excision and routine histological sampling was performed routinely. 
Fig. 2 Histological analysis of gynecomastia specimens. (HEstain, 1:100) Left: typical pattern of true fibrous gynecomastia with mild ductal hyperplasia. Right: spindle-cell hemangioendothelioma in gynecomastia tissue
Table 2 Early major and minor complications in 100 patients. (*requiring surgical revision). At total of 31 complications occurred in 100 patients.

Table 3 Risk factors for postoperative complications

Fig. 3 Left: 23-year-old patient with idiopathic, unilateral gynecomastia (stage IIb). Right: 3 months following subcutaneous mastectomy with assisting liposuction
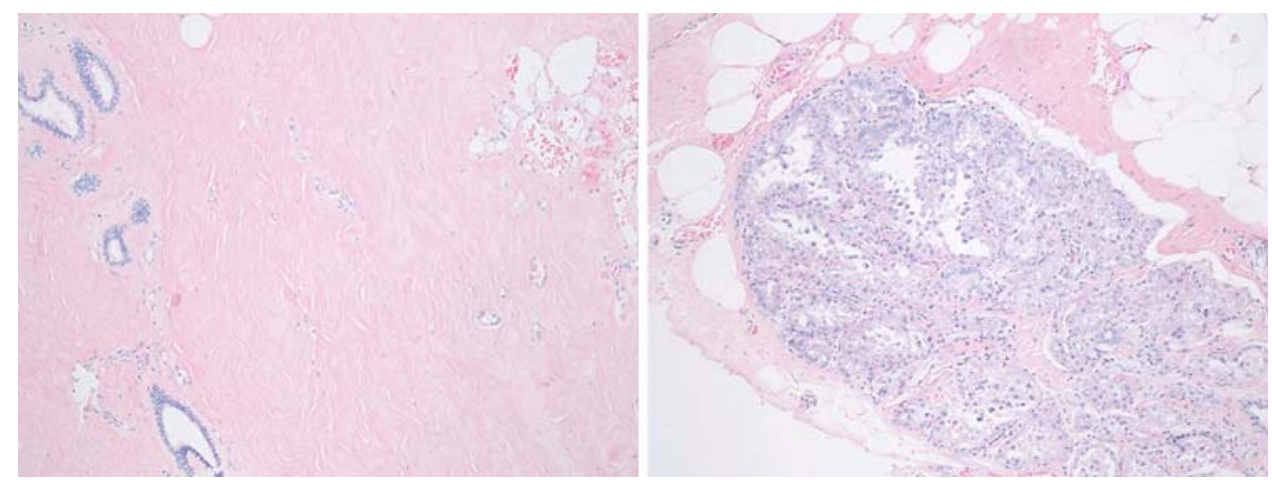

\begin{tabular}{lllll}
\hline & Stage IIa $(n=42)$ & Stage IIb $(n=31)$ & Stage III $(n=24)$ & Total \\
\hline Hematoma & 2 & 5 & 2 & $9(* 4)$ \\
Seroma & 4 & 1 & 3 & $8(* 3)$ \\
Epidermolysis & 3 & 4 & & 7 \\
Nipple hypesthesia & 2 & 3 & 1 & 6 \\
Wound necrosis & & 1 & & 1 \\
Total & $11 / 42$ & $14 / 31$ & $6 / 24$ & $31 / 100$ \\
\hline
\end{tabular}

\begin{tabular}{llc}
\hline Risk factors & Complications & $p$ value \\
\hline Subcutaneous mastectomy alone versus with liposuction & $13.9 \%$ versus $15 \%$ & 0.69 \\
Smokers versus nonsmokers & $21 \%$ versus $18 \%$ & 0.125 \\
Overweight versus lean $\left(\mathrm{BMI}>25 \mathrm{~kg} / \mathrm{m}^{2}\right)$ & $36 \%$ versus $14 \%$ & $* 0.0373$ \\
Resected weight $>40 \mathrm{~g}$ versus $<40 \mathrm{~g}$ & $51 \%$ versus $2 \%$ & $* 0.0158$ \\
\hline
\end{tabular}
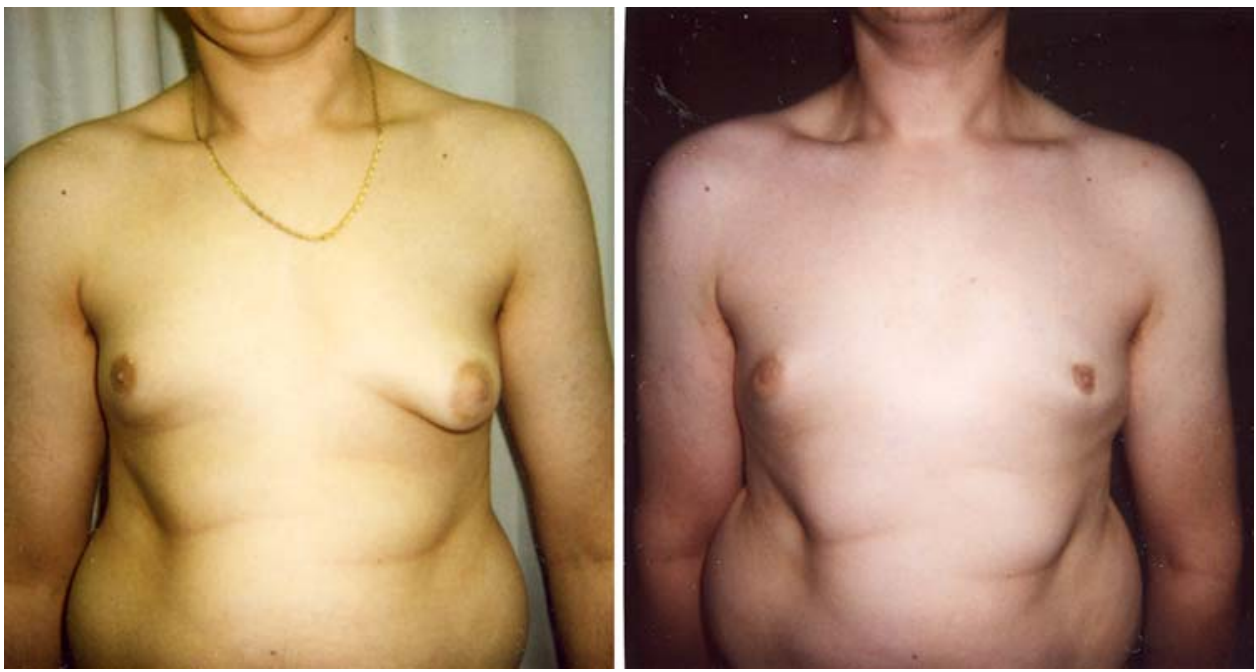

Thus the major concern with the exclusive use of liposuction is the lack of histopathological analysis of the resected tissue. Even though it is technically possible to submit tissue pieces from liposuction to a histopathological analysis [14], this has been performed only rarely, and the results are difficult to interpret due to tissue damage and consistency. In our series, $3 \%$ of patients were diagnosed as having atypical cellular findings: The spindle-cell hemangioendothelioma describes a number of vascular lesions that vary not only in their morphologic features but, more important, in their biological behavior [15]. In the recent WHO classification of mesenchymal tumors, hemangioendotheliomas are defined as vascular neoplasms of "intermediate" or "borderline" malignancy, and spindle- 
Fig. 4 Left: 21-year-old patient with idiopathic, bilateral gynecomastia mimicking tubular breast deformity (stage IIa). Right: 5 months following subcutaneous mastectomy and mastopexy
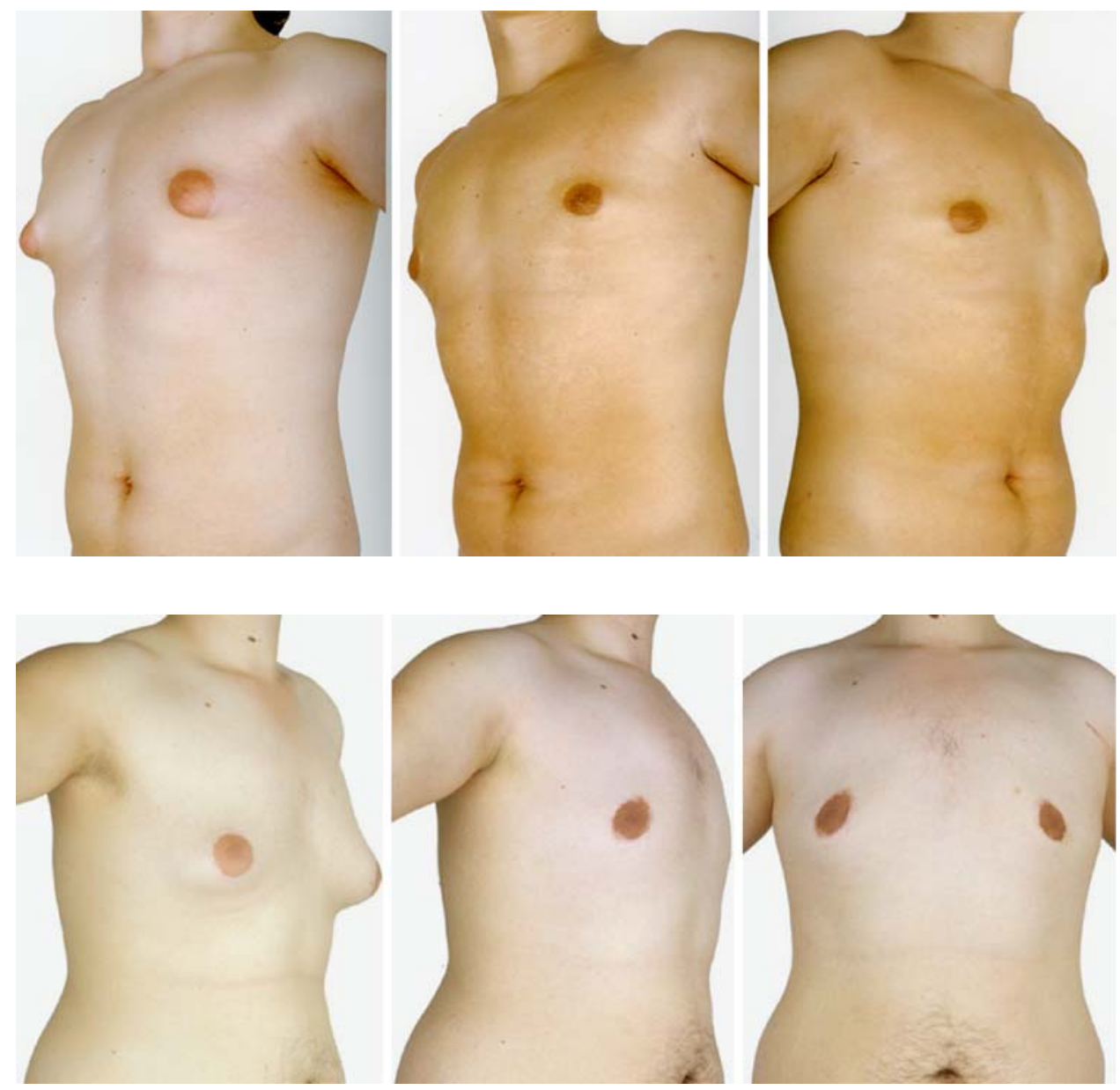

Fig. 5 Left: 20-year-old patient with idiopathic, bilateral gynecomastia (stage IIb).

Right: 6 months following subcutaneous mastectomy with assisted liposuction cell hemangioendotheliomas are included in this category [15].

Another histolopathologic finding in the present study was a breast papilloma, which also requires surgical excision in the co-presence of atypical ductal hyperplasia due to the increased rate of associated neoplasia [16]. Bilateral atypical ductal hyperplasia in gynecomastia specimens has been described by other authors [17]. Nevertheless, it is important to emphasize, that there is no convincing evidence linking gynecomastia with increased incidence of male breast cancer [18]. In contrast to gynecomastia, male breast cancer has a peak at 71 years, and it usually presents as a painless lump or nipple retraction [18]. However, this does not eliminate the need for a histological examination of the resected tissue [19-23]. Voulliaume et al. report a case in which a patient received liposuction for "gynecomastia," which later proved to be established male breast cancer. They point out the problem of dissemination of malignant cells into healthy tissue during the liposuction procedure [19]. Other authors have also described that breast enlargement in young men is not always benign gynecomastia: malignant tumours such as breast carcinoma may be present in the midst of florid gynecomastia, even in a young patient [20]. DeBree et al. describe a 22-year-old man initially diagnosed with unilateral gynecomastia, in which histological analysis revealed an invasive ductal carcinoma of the breast [21]. In a recent publication, Staerkle et al. report on synchronous bilateral ductal carcinoma in situ in a young man presenting with bilateral gynecomastia [22]. Wadie et al. describe a case of a 16year-old boy with bilateral gynecomastia, in which the histological work-up revealed a ductal carcinoma in situ [23].

Taken together, these data emphasize the need for a histological analysis because gynecomastia may be harboring a neoplasia. Liposuction as an exclusive procedure should be limited to cases of pure pseudogynecomastia, in which preoperative assessment shows the presence of an isolated lipohypertrophy with no sign of glandular enlargement.

The classic semicircular-periareolar inferior incision proved to be a valid access in grade I-IIb gynecomastia in this study. Aslan et al. suggest a modified surgical access that uses a W-shaped periareolar-transareolar-perithelial incision to provide wide exposure of the resection area and to facilitate nipple-areolar reduction in advanced stages 
Fig. 6 Left: 46-year-old patient with bilateral pseudogynecomastia (stage III). Right: 12 months following subcutaneous mastectomy and mastopexy

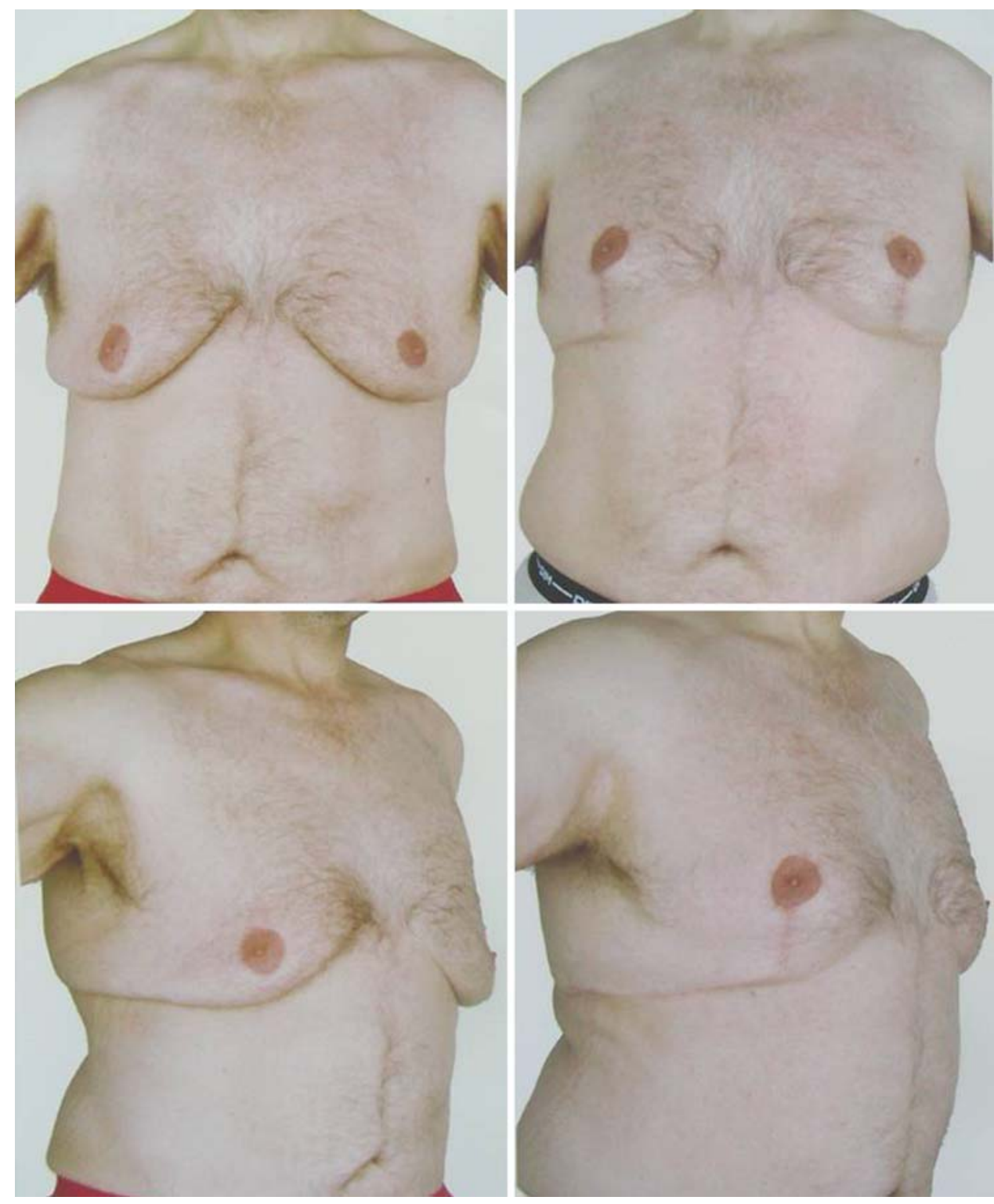

[24]. In cases with redundant skin (IIb-III), simultaneous medialization and cranialization of the nipple-areola complex completing the semicircular medial incision to a periareolar de-epthelialzation were useful. Rarely, large ptosis in grade III cases of gynecomastia may require formal breast reduction with an I- or T-shaped pattern.

The most frequent complication of subcutaneous mastectomy in the present study was postoperative bleeding and hematoma or seroma formation. This finding is consistent with the results of other series, which have described an overall complication rate of up to $28 \%$ in all patients [4, 8]. The statistically significant increase of complications in resections exceeding $40 \mathrm{~g}$ of breast tissue is of clinical consequence to the postoperative treatment. The larger wound area and resection weight in overweight patients (BMI $>25 \mathrm{~kg} / \mathrm{m}^{2}$ ) may explain the higher complication rates in this group. Based on the analysis of our retrospective data, we have now extended the duration of the compressive dressing to a 3-week period following surgery, especially in overweight patients and larger resections.

To prevent hematoma and seroma formation, we advise patients to refrain from physical activities for a period of 4 6 weeks postoperatively. So far, we have observed no further hematoma or seroma in these patients. In overweight patients and in cases of large resections, surgeons should consider leaving compressive dressings beyond hospital stay, thus maintaining prolonged wound compression.

The use of additional liposuction may improve the postoperative results, especially if the excision of an enlarged gland results in a concave deformity of the remnant breast. Some authors have even suggested the exclusive use of liposuction in the surgical treatment of 
gynecomastia $[6,7,13]$. Hodgson et al. report on a small series of 13 patients with gynecomastia treated exclusively by ultrasonic liposuction [13]. They report no early postoperative complications of hematoma, seroma, infection, or thermal injuries, and they state that "ultrasound-assisted liposuction can be attempted for all types of gynecomastia" [13]. In another study, 61 patients with grade I-III gynecomastia were treated with liposuction only (suctionassisted lipectomy and ultrasound-assisted liposuction) [7]. Although the authors describe no early postoperative complications, $13 \%$ of the patients required a open excision of remaining breast tissue and redundant skin 6-9 months postoperatively [7].

In our study, unilateral gynecomastia was found in $40 \%$ of the patients. In other large studies the incidence of unilateral involvement varies from $14 \%$ to $51 \%$ [3, 8]. However, unilateral gynecomastia may not be as unique as anticipated by some authors. Diagnostic reports describe unilateral gynecomastia in about $40 \%$ of men who undergo mammography [25] or high-frequency color Doppler ultrasonography [26] for breast enlargement due to gynecomastia.

In conclusion, the surgical treatment of gynecomastia requires an individual approach, depending on the grade of male breast hypertrophy. Based on the presented data, true glandular hypertrophy requires a surgical glandular tissue excision and subsequent histological examination, thus avoiding oncological pitfalls. Liposuction can be used as an additional technique for optimizing the esthetic result following the excision of the glandular tissue. Exclusive liposuction should be restricted to cases of pseudogynecomastia. In larger resections and in overweight patients, caution must be taken, because complications including bleeding and hematoma formation may be increased. In patients presenting with massive skin redundancy (grade III), the treating surgeon should be experienced in breast reduction techniques. The presented series indicate that subcutaneous mastectomy with or without additional handassisted liposuction provides an excellent outcome with extremely low recurrence rates.

\section{References}

1. Braunstein GD (1993) Gynecomastia. N Engl J Med 328:490-495

2. Gabra HO, Morabito A, Bianchi A, et al. (2004) Gynecomastia in the adolescent; a surgically relevant condition. Eur J Pediatr Surg 14:3-6

3. Colombo-Benkmann M, Buse B, Stern J, et al. (1999) Indications for and results of surgical therapy for male gynecomastia. Am J Surg 178:60-63
4. Steele SR, Martin MJ, Place RJ (2002) Gynecomastia: complications of the subcutaneous mastectomy. Am Surg 68:210-213

5. Boljanovic S, Axelsson CK, Elberg JJ (2003) Surgical treatment of gynecomastia: liposuction combined with subcutaneous mastectomy. Scand J Surg 92:160-162

6. Fruhstorfer BH, Malata CM (2003) A systematic approach to the surgical treatment of gynecomastia. Br J Plast Surg 56:237-246

7. Rohrich RJ, Ha RY, Kenkel JM, et al. (2003) Classification and management of gynecomastia: defining the role of ultrasound assisted liposuction. Plast Reconstr Surg 111:909-923

8. Wiesman IM, Lehman JA, Parker MG, et al. (2004) Gynecomastia - an outcome analysis. Ann Plast Surg 53:97-101

9. Tashkandi M, Al-Qattan MM, Hassanain JM, et al. (2004) The surgical treatment of high-grade gynecomastia. Ann Plast Surg 53:17-20

10. Simon BE, Hoffman S, Kahn S (1973) Classification and surgical correction of gynecomastia. Plast Reconstr Surg 51:48-56

11. Webster JP (1946) Mastectomy for gynecomastia through a semicircular intra-areolar incision. Ann Surg 124:557

12. Benelli L (1990) A new periareolar mammaplasty: the "round block" technique. Aesthetic Plast Surg 14:93-100

13. Hodgson ELB, Fruhstorfer BH, Malata CM (2005) Ultrasonic liposuction in the treatment of gynecomastia. Plast Reconstr Surg 116:646-653

14. Prado AC, Castillo PF (2005) Minimal surgical access to treat gynecomastia with the use of a power assisted arthroscopic cartilage shaver. Plast Reconstr Surg 115:939-942

15. Mentzel T (1998) Hemangioendotheliomas-evolution of a concept of a heterogeneous group of vascular neoplasms (in German). Verh Deutsch Ges Pathol 82:99-111

16. Agoff SN, Lawton TJ (2004) Papillary lesions of the breast with and without atypical ductal hyperplasia: can we accurately predict benign behaviour from core needle biopsy? Am J Clin Pathol 122:440-443

17. Prasad V, King JM, McLeay W (2005) Bilateral atypical ductal hyperplasia, an incidental finding in gynecomastia. Breast $14: 317-321$

18. Fentiman IS, Fourquet A, Hortobagyi GN (2006) Male breast cancer. Lancet 367:595-604

19. Voulliaume D, Vasseur C, Delaporte T, et al. (2003) An unusual risk of liposuction: liposuction of a malignant tumor (in French). Ann Chir Plast Esthet 48:187-193

20. Fodor PB (1989) Breast cancer in a patient with gynecomastia. Plast Reconstr Surg 84:976-979

21. DeBree E, Tsagkatakis T, Kafousi M, et al. (2005) Breast enlargement in young men not always gynecomastia. Breast cancer in a 22-year-old man. Aust N Z J Surg 75:914-916

22. Staerkle RF, Lenzlinger P, Suter SL, et al. (2006) Synchronous bilateral ductal carcinoma in situ of the male breast associated with gynecomastia in a 30-year-old patient following repeated injections of stanozolol. Breast Cancer Res Treat 97:173-176

23. Wadie GM, Banever GT, Moriarty KP, et al. (2005) Ductal carcinoma in situ in a 16-year-old adolescent boy with gynecomastia: a case report. J Pediatr Surg 40:1349-1353

24. Aslan G, Tuncali D, Terzioglu A, et al. (2005) Periareolar-transareolar-perithelial incision for the surgical treatment of gynecomastia. Ann Plast Surg 54:130-134

25. Cooper RA, Gunter BA, Ramamurthy L (1994) Mammography in men. Radiology 191:651-656

26. Caruso G, Ienzi R, Piovana G, et al. (2004) High-frequency ultrasound in the study of male breast palpable masses. Radiol Med (Torino) 108:185-193 